\title{
A Importância da Brinquedoteca no Ambiente Hospitalar
}

\author{
The Importance of Toy Library in the Hospital Environment
}

Monique Spindolla Mexias dos Santos ${ }^{\dagger *}$, Suely Cristina de Souza Fernandes Crahim

Como citar esse artigo. dos Santos, MSM; Crahim, SCSF. A Importância da Brinquedoteca no Ambiente Hospitalar. Revista Mosaico. 2019 Jul/Dez.; 10 (2): SUPLEMENTO 11-15.

\section{Resumo}

Com o intuito de demonstrar como a Brinquedoteca hospitalar pode trazer benefícios no tratamento e recuperação das crianças hospitalizadas, o presente artigo destaca a importância que o brincar traz para a vida da criança, ajudando-a a passar por momentos difíceis diante da internação, amenizando seu sofrimento e proporcionando um espaço onde elas possam expressar seus sentimentos e emoções, bem como destacar a importância do papel do psicólogo junto às famílias, equipe de saúde e crianças internadas, contribuindo para a compreensão e adesão ao tratamento a partir do lúdico no ambiente da Brinquedoteca hospitalar, oferecendo grupos de apoios para as famílias e mediando a relação delas com a equipe de saúde visando à melhora e bem estar do paciente.

Palavras-Chave: Brinquedoteca Hospitalar, Hospitalização Infantil, Psicologia.

\begin{abstract}
With the purpose of demonstrating how the hospital toy library can bring benefits to the treatment and recovery of hospitalized children, this article highlights the importance that playing brings to the child's life, helping them to go through difficult moments of hospitalization, easing the pain and providing a space where they can express their feelings and emotions, as well as highlight the importance of the role of the psychologist with families, health staff and hospitalized children, contributing to the understanding and adherence to the treatment from the playful environment in the toy library providing support groups for families and mediating their relationship with the health team in order to improve the patient's well-being.

Keywords: Hospital's Toy Library, Child Hospitalization, Psychology.
\end{abstract}

\section{Introdução}

A Brinquedoteca é um espaço criado para estimular a criança a brincar e colaborar para que ela desenvolva a criatividade, possibilitando-a estar em contato com vários tipos de brinquedos fazendo com que exerça a socialização e afetividade uma vez que dentro da Brinquedoteca estará em contato com outras crianças.

A Brinquedoteca hospitalar tem o objetivo de auxiliar a criança internada e seus familiares a passarem por esse momento de uma forma mais "tranquila" uma vez que nesse espaço eles poderão deixar por alguns momentos as tensões, medos, ansiedades que a hospitalização traz. Auxilia também na relação com os profissionais da saúde para que os procedimentos se tornem menos dolorosos e invasivos.

Através do lúdico a criança poderá expressar seus sentimentos em relação à internação, que muitas vezes não consegue dizer o que está sentindo, porém na brincadeira ela transmitirá e permitirá que sejam observados seus medos e fantasias diante da internação e tratamento.

Segundo Macedo (2008, p.65):

É importante mostrar como o brincar e a criação de brincadeiras na enfermaria, UTI e ambulatório podem

Afiliação dos autores: †Psicóloga, graduada pela Universidade Severino Sombra (Vassouras/RJ, Brasil), pós-graduada em Educação Especial - Deficiência Mental pela Universidade Federal do Estado do Rio de Janeiro - UNIRIO (Rio de Janeiro- RJ, Brasil), pós-graduanda em Psicologia Hospitalar e da Saúde pela Universidade de Vassouras (Vassouras/RJ, Brasil).

\$ Pedagoga; Mestra em Educação Matemática; Especialista em Psicopedagogia pela Universidade Severino Sombra; Professora Assistente III do Curso de Graduação em Psicologia e Pedagogia da Universidade de Vassouras; Coordenadora e Psicopedagoga do Núcleo de Apoio Psicopedagógico da Universidade de Vassouras (Vassouras/RJ, Brasil). 
auxiliar o tratamento da criança doente, amenizando seu sofrimento e fortalecendo o vínculo entre ela e seu acompanhante, fazendo com que se desenvolva uma participação mais afetiva entre eles durante a internação. Auxilia também a melhora do sofrimento observado nas crianças e em seus acompanhantes, criando um ambiente mais humanizado, no qual as pessoas têm a oportunidade de compartilhar suas percepções e experiências a respeito da doença e das transformações que esta acarreta.

O presente artigo tem o objetivo de compreender a importância e os benefícios que a Brinquedoteca hospitalar traz tanto para a criança internada, quanto para seus acompanhantes e profissionais de saúde ao conseguirem lidar melhor e ter mais resultados e adesões ao tratamento, partindo da ludicidade. Assim como, destacar o papel e a importância da psicologia nesse ambiente, favorecendo a aproximação da equipe médica com a família da criança internada e auxiliandoos para que eles passem por esse momento da melhor forma possível amenizando o sofrimento.

\section{Definição de Brinquedoteca}

A Brinquedoteca é um espaço criado para estimular a criança a brincar e colaborar para que ela desenvolva a criatividade, possibilitando-a estar em contato com vários tipos de brinquedos fazendo com que ela exerça a socialização e afetividade uma vez que dentro da Brinquedoteca ela estará em contato com outras crianças.

Para Viegas (2003) apud Carvalho e Scatolini (2016, p.11):

[...] no espaço da Brinquedoteca se tem a certeza de que, ao brincar, a criança constrói seu sistema de valores, aprende a interagir com o outro, convive com a natureza e com ela mesma. Brincando, ela torna seus sonhos uma bela realidade e não perde o direito de ser criança.

Segundo Oliveira et al. (1999) apud Carvalho e Scatolini (2016, p. 11), "Brinquedoteca é um espaço lúdico apropriado para que as habilidades características do desenvolvimento infantil sejam estimuladas".

Dentre os vários tipos de Brinquedoteca podemse destacar quatro classes: Brinquedoteca Comunitária, Brinquedoteca Psicopedagógica, Brinquedoteca Hospitalar e Brinquedoteca Especializada (de acordo com a demanda e o público do local).

\section{História da Brinquedoteca}

A Brinquedoteca surgiu em 1934 em Los Angeles, onde as crianças levavam brinquedos emprestados para casa com o objetivo de brincar.

De acordo com Cunha (1992) apud Gimenes e Teixeira (2011, p. 146):
[...] a sugestão para a criação do espaço infantil surgiu após a direção de uma escola perceber que os alunos chegavam atrasados nas aulas devido a uma loja de brinquedos que havia no percurso para a escola, cujo proprietário teria reclamado de alguns furtos de brinquedos feitos pelos alunos. Após esses episódios resolveu-se criar esse serviço comunitário.

No ano de 1963 na Suécia foi criada a LEKOTEK (ludoteca em sueco), que atendia somente crianças portadoras de necessidades especiais. Nesse espaço as crianças eram estimuladas e os pais eram orientados por profissionais especializados de como poderiam estimulálas em casa. Em 1967 surgiram as TOYLIBRARIES (bibliotecas de brinquedos).

No Brasil, no início do ano de 1971 foi inaugurado o Centro de Habilitação da Associação de Pais e Amigos dos Excepcionais (APAE), que tinha o objetivo de realizar uma exposição de brinquedos pedagógicos para que as pessoas pudessem estar por dentro do que o mercado oferecia para as crianças. Com o sucesso do evento, em 1973 o local se transformou em uma ludoteca.

As Brinquedotecas no Brasil começaram a surgir na década de 1980. Em 1984, fundou-se a Associação Brasileira de Brinquedotecas (ABBri). De acordo com Cunha (2008), "A Brinquedoteca brasileira diferenciase das Ludotecas e das TOYLIBRARIES, porque estas têm seu trabalho direcionado para o empréstimo de brinquedos, enquanto que, na BRINQUEDOTECA brasileira, o trabalho está focado no brincar propriamente dito".

\section{A Importância da Brinquedoteca no ambiente Hospitalar}

Toda criança tem o direito de brincar garantido por lei, o brincar tornou-se legalizado e garantido mundialmente em 1959, quando a Organização das Nações Unidas (ONU) declarou os Direitos da Criança. No Brasil esse direito se confirmou com a Constituição Federal de 1988 (BRASIL, 1988), com o Estatuto da Criança e do Adolescente (ECA) (BRASIL,1990), com a Lei $\mathrm{n}^{\circ}$ 9.394, que estabelece as Diretrizes e Bases da Educação Nacional de 1996 (BRASIL,1996), e em março de 2005, a Lei das Brinquedotecas Hospitalares (LEI $n^{\circ}$ 11.104) (BRASIL,2005), que dispõe sobre a obrigatoriedade de instalação de Brinquedoteca em unidades de saúde que ofereçam atendimento pediátrico em regime de internação. Segundo Cunha (2001, p. 96) apud Gimenes e Teixeira (2011, p. 197): “a Brinquedoteca hospitalar tem a finalidade de tornar a estadia da criança no hospital menos traumatizante mais alegre, possibilitando assim melhores condições para a sua recuperação".

O brincar desperta e estimula as crianças em diversas áreas, como por exemplo: coordenação 
motora, atenção, concentração, iniciativa, autoestima, autonomia, independência, limites, respeito, regras, entre outras, e contribui para seu desenvolvimento emocional e cognitivo, para sua socialização e ampliação de sua comunicação, uma vez que a partir da brincadeira ela estará em contato com outras pessoas. Através das brincadeiras as crianças são capazes de expressar suas emoções e sentimentos, seus medos e fantasias.

Segundo Varêda (2007) apud Carvalho e Scatolini (2016, p. 32):

Em uma abordagem lúdica, atendendo às escolhas e desejos da criança, a atividade é estabelecida pelo ato de brincar, incentivando a exteriorização de emoções, melhorando a autoestima, buscando seu desenvolvimento global e o desenvolvimento de habilidades funcionais.

Quando uma criança precisa ser submetida a uma internação hospitalar e sai da sua rotina, a adaptação à nova realidade muitas vezes é difícil, ainda mais pelos procedimentos invasivos que muitas vezes causam dor, além daquela já sentida pela doença, exames diários, pelo novo ambiente cheio de regras, restrições alimentares, pela distância dos demais familiares, pelo afastamento dos amigos e da escola, fazendo com que no começo ela venha a apresentar fantasias e medos diante dessa nova realidade.

Para Jabardo e Teixeira (2008) apud Gimenes e Teixeira (2011, p. 198):

A criança hospitalizada precisa de atenção e cuidados médicos, mas também necessita continuar sendo criança. Afinal, foi-lhe tirado o direito de brincar com os amigos, modificaram sua rotina, separaram-na dos próprios brinquedos, sendo natural que se angustie diante do enfrentamento da realidade hospitalar.

\section{Segundo Silva (2012) apud Diogo (2016, p. 7):}

[...] é na infância que se configura as primeiras relações sociais, ou seja, na família e na escola, no caso de crianças hospitalizadas essa socialização é importantíssima, pois é através dela que a criança passa a compreender e elaborar os mecanismos para enfrentar a doença, trazendo ressonâncias para a vida da criança. Enquanto as crianças constroem nas escolas e ambientes familiares suas relações e interações sociais, a criança doente constrói no ambiente hospitalar seu local de sociabilidade.

A Brinquedoteca dentro do hospital auxiliará a criança para que ela passe por este processo de hospitalização da melhor forma possível adquirindo confiança, facilitando a adaptação e minimizando seu sofrimento diante desse momento. É através da brincadeira que conseguirá entender o que está acontecendo com ela, quais os procedimentos que serão realizados e quais os sintomas que a doença pode trazer. É um espaço onde a criança poderá se aproximar um pouco da rotina que tinha fora do hospital, percebendo que outras crianças também estão passando por isso, fazendo com que ela se sinta mais confortada diante de tanta mudança. Na Brinquedoteca a criança pode expressar o que está sentindo com essa nova realidade, demonstrando seus medos, angústias e dificuldades diante da situação vivida.

Acriançaqueéhospitalizadatem dificuldade decompreendero que se passa com ela, de assimilar a doença e os procedimentos médicos necessários para o tratamento. $\mathrm{O}$ impacto da hospitalização permeia o imaginário infantil podendo acarretar consequências negativas (SILVA, 2012, p. 01 - 02).

O espaço da Brinquedoteca também ajudará na reaproximação dos pais com a criança, fazendo com que naquele local possam estar em contato com seus filhos e brincar de uma forma mais leve e descontraída. Auxiliará também como uma forma de refúgio para esses pais que, ao verem seus filhos naquela situação ficam nervosos e estressados. Algumas Brinquedotecas hospitalares disponibilizam oficinas voltadas para os pais, para que eles também possam sair um pouco da rotina hospitalar por alguns momentos, tornando a estadia naquele ambiente, melhor.

Para a equipe médica, a Brinquedoteca poderá ajudar na aproximação com a criança e seus familiares, facilitando os procedimentos e exames, tornandoos menos dolorosos e contribuindo para a adesão ao tratamento, podendo aumentar as possibilidades de recuperação da criança.

Segundo Fortuna (2008, p. 39), o resultado de uma pesquisa feita no Centro Infantil Boldrini revelou que "a utilização da arte como recurso terapêutico torna o paciente mais colaborativo no tratamento, alivia a angústia diante de procedimentos invasivos e diminui a hostilidade ao ambiente hospitalar".

Uma das brincadeiras mais importantes é a de "faz-de-conta", onde a criança pode fingir ser o que quiser e imaginar estar em qualquer lugar. A criança pode até mesmo brincar de médico e expressar, a partir do lúdico, tudo que o está sentindo devido à internação, fazendo com que ela represente a realidade vivida do modo como vê.

Segundo Oliveira (2008, p.29):

O simbolismo expresso na brincadeira de "faz-deconta" contém uma carga emocional tão profunda e representativa de conteúdos e mecanismos inconscientes que se aproximam das representações oníricas, prevenindo e combatendo o estresse da hospitalização, assim como resgatando mecanismos saudáveis de auto-recuperação, em seus aspectos complementares físicos e psicológicos.

É a partir dessas brincadeiras de "faz-de-conta", teatrinho, bonecas, entre tantas outras, que podem estar presentes dentro da Brinquedoteca hospitalar, que a criança vai conseguir assimilar o que está acontecendo com ela de uma forma menos assustadora e agressiva. 
Além de todos esses benefícios que a Brinquedoteca hospitalar traz para a criança internada, o principal é o investimento e o cuidado no bem-estar. É importante que apesar de estar num ambiente diferente e fora da sua rotina, a criança não deixe de ser criança e tenha oportunidade de brincar e se divertir, de expressar suas emoções e sentimentos, de ser ouvida, de poder questionar o que está acontecendo e o que será feito com ela. E principalmente de aprender e estar o mais próximo possível da sua realidade fora do hospital, para que ela não tenha uma experiência traumática desse evento na sua vida.

É fundamental que as crianças acamadas que não podem sair dos seus leitos para irem até a Brinquedoteca, tenham a oportunidade de brincar também. Se elas não podem ir à Brinquedoteca, a Brinquedoteca vai até elas. Claro que não terá acesso a todos os brinquedos, porém podem ser oferecidos alguns que sejam de fácil transporte, que não atrapalhem a movimentação da enfermaria e não incomodem os demais pacientes.

\section{Brinquedistas}

Para que a Brinquedoteca tenha um bom funcionamento é de extrema importância que se tenham pessoas capacitadas e essas pessoas são chamadas de Brinquedistas.

Os brinquedistas são importantes, pois são eles que vão cuidar do espaço da Brinquedoteca para que esteja sempre apta a receber seus usuários e para que aquele lugar seja o mais confortável possível. São eles que vão apresentar o espaço para as crianças e explicar o funcionamento do ambiente.

Brinquedistas Hospitalares devem saber minimamente o que cada paciente que frequenta a Brinquedoteca tem, qual o tipo de doença e quais os procedimentos e tratamentos que estão sendo realizados neles.

Segundo Cunha (2008, p.75),

\begin{abstract}
Aspectos psicológicos resultantes da hospitalização precisam ser atendidos, assim como devem ser consideradas suas condições físicas e respeitados seus limites e suas características. O conhecimento da doença, suas particularidades, o prognóstico, o tratamento que está recebendo são aspectos importantes na compreensão e nos cuidados que elas devem receber na Brinquedoteca.
\end{abstract}

A partir do entendimento dos procedimentos que serão realizados nas crianças os brinquedistas poderão oferecer brinquedos e brincadeiras que venham a facilitar o entendimento sobre tudo o que estão passando e vivendo.

\section{Higienizações das Brinquedotecas Hospitalares}

A Brinquedoteca hospitalar necessita de alguns cuidados muito importantes, por estarem localizadas dentro de um hospital, as chances de contaminação por bactérias e vírus são grandes, e é por esse motivo que a equipe deve estar muito atenta a higienização do ambiente. $\mathrm{O}$ ambiente deve ser limpo e desinfetado com frequência, os brinquedos devem ser sempre lavados. É importante ressaltar que alguns brinquedos não são apropriados para a Brinquedoteca hospitalar, pois não podem ser lavados e nem higienizados. Os brinquedistas e todos os frequentadores da Brinquedoteca devem higienizar as mãos antes e depois de manipular os objetos e brinquedos.

Segundo Silva e Matos (2009, p. 09), apud Diogo (2016, p. 9), "a Brinquedoteca hospitalar requer alguns cuidados especiais com os brinquedos. Não se pode esquecer que a infecção hospitalar é um grande problema na saúde pública e alguns fatores contribuem para a contaminação". É necessário que após a utilização dos brinquedos, os mesmos sejam higienizados com detergente, sabão e álcool $70 \%$, que é o ideal para uma nova utilização posteriormente.

\section{A atuação do Psicólogo na Brinquedoteca Hospitalar}

O psicólogo dentro da Brinquedoteca hospitalar poderá contribuir para que os efeitos da doença e do tratamento sejam amenizados tanto para a criança como para seus acompanhantes, levando em conta o bemestar biopsicossocial de todos os envolvidos, assim como visa facilitar a relação entre paciente, equipe de saúde e familiares.

Através do trabalho junto aos brinquedistas a partir do lúdico, o psicólogo será capaz de ajudar a criança a entender o que está acontecendo, para que ela encare a situação de uma forma mais tranquila e que possa aderir melhor ao tratamento. O psicólogo através da brincadeira poderá ajudar a criança a lidar melhor com suas angústias, medos, ansiedades e estresse recorrente da internação, possibilitando o seu bem-estar e a elaboração dos seus sentimentos diante da situação que vem enfrentando. E para que isso ocorra é fundamental que o profissional da psicologia saiba minimamente o diagnóstico e tratamento que foi prescrito para cada criança, que conheça sua história de vida e o modo como adoeceu para que assim possa auxiliá-la da melhor maneira possível no enfrentamento da doença.

De acordo com Mesquita, Silva e Júnior (2013, p. 06), 
A criança em especial pelo fato de ainda estar desenvolvendo seu repertorio de experiência, precisa de apoio para enfrentar possíveis efeitos negativos relacionados a eventos traumáticos, ao sentimento de insegurança, a falta de ajuda, de medo intenso e de ansiedade decorrentes da hospitalização.

O contato com os familiares também é de extrema importância, pois o psicólogo pode ser o mediador entre a família e a equipe de saúde, ajudando essa família a esclarecer qualquer tipo de dúvidas sobre o tratamento, procedimentos e internação da criança. Segundo Campos (1995, p.94) "O psicólogo pode fazer os esclarecimentos lutilizando explicações verbais, cartazes, desenhos, gráficos, sendo, muitas vezes, a ponte de ligação entre o hospital, a equipe de profissionais e a família." Poderá promover grupos com as famílias de crianças internadas, para que possam trocar experiências, dividir seus sentimentos, medos, angústias e tirar dúvidas, e ao perceberem que outras pessoas estão passando pela mesma situação que elas, conseguirem adquirir força e coragem para enfrentarem a situação.

É importante para o trabalho do psicólogo que ele entenda qual o significado da doença para o paciente e para sua família, como se deu a internação e como foi a adaptação e rotina hospitalar, para poder abordá-los da maneira correta e obter resultados positivos.

\section{Considerações finais}

A partir do estudo bibliográfico podemos perceber a importância e o impacto positivo que a Brinquedoteca hospitalar traz para as crianças hospitalizadas, proporcionando um ambiente diferente no hospital, em que sejam acolhidas, ouvidas, e que tenham a oportunidade de se aproximar da sua realidade fora do hospital, fazendo com que elas sintam-se melhor e livres por alguns instantes do clima pesado que a rotina hospitalar exige.

A Brinquedoteca também atua de forma positiva na relação dos familiares com as crianças internadas, pois é o momento em que eles podem deixar a doença do lado de fora e brincar com seus filhos de forma saudável. Do mesmo modo que auxilia na aproximação dessas crianças com a equipe de saúde, muitas vezes para tornar alguns procedimentos menos assustadores e doloridos, a equipe de saúde recorre ao lúdico.

Apsicologia dentro da Brinquedoteca vem atuando de forma a amenizar o sofrimento do paciente e ajudar na relação entre equipe de saúde, os familiares e os pacientes. Apesar de o psicólogo ser fundamental nesse processo e sua participação dentro da Brinquedoteca hospitalar ser de grande valia para evolução e promoção do bem-estar biopsicossocial do paciente e seus familiares, há uma necessidade muito grande de mais estudos voltados para isso, pois encontramos na literatura muitas informações sobre o psicólogo hospitalar, mas o psicólogo dentro da
Brinquedoteca hospitalar não.

Conclui-se que a Brinquedoteca hospitalar não é só um local aonde crianças internadas vão para brincar, foi observado que cada brincadeira pode representar algo e ajudar no processo de internação e cura do paciente, percebeu-se a importância dos profissionais envolvidos e dos familiares para que se tenham respostas positivas no tratamento dos pacientes.

\section{Referências}

BRASIL. Constituição (1988). Constituição da República Federativa do Brasil. Brasília, DF, 1988.

BRASIL. Lei n ${ }^{8.069}$, de 13 de Julho de 1990. Dispõe sobre o Estatuto da Criança e do Adolescente (ECA). Brasília, DF, 1990.

BRASIL. Lei n ${ }^{\circ} 9.394$ de 20 de Dezembro de 1996. Estabelece as Diretrizes e Bases da Educação Nacional. Brasília, DF, 1996.

BRASIL. Lei $n^{\circ} 11.104$ de 21 de Março de 2005. Dispõe sobre a Obrigatoriedade de Instalação de Brinquedotecas nas Unidades de Saúde que Ofereçam Atendimento Pediátrico em Regime de Internação. Brasília, DF, 2005.

CAMPOS, T. C. P., Psicologia Hospitalar: a atuação do psicólogo em hospitais. São Paulo: EPU, 1995.

CARVALHO, A. F. C. T., SCATOLINI, H. M. N., Brinquedoteca e Terapia Ocupacional: Ações Interdisciplinares. Rio de Janeiro: Rubio, 2016.

CUNHA, N. H. S. Brinquedista Hospitalar. In: VIEGAS, D. Brinquedoteca Hospitalar: isto é humanização. Associação Brasileira de Brinquedotecas. 2. ed. Rio de Janeiro: Wak, 2008.

DIOGO, J. D. S. Brinquedoteca Hospitalar: a importância do brincar durante o processo de tratamento infantil na internação. 2016. Disponível em file:///E:/Pós\%20Psic\%20Hospitalar/A1010.pdf Acesso em 25/01/2019. Acesso em: 10 mar. 2019.

FORTUNA, T. R. Brincar, Viver e Aprender: Educação e Lucidade no Hospital. In: VIEGAS, D. Brinquedoteca Hospitalar: isto é humanização. Associação Brasileira de Brinquedotecas. 2. ed. Rio de Janeiro: Wak, 2008.

GIMENES, B. P. TEIXEIRA, S. R. O. Brinquedoteca - Manual em educação e saúde. São Paulo: Cortez, 2011.

MACEDO, J. A Criação de uma Brinquedoteca Hospitalar com Enfoque Psicodramático. In: VIEGAS, D. Brinquedoteca Hospitalar: isto é humanização. Associação Brasileira de Brinquedotecas. 2. ed. Rio de Janeiro: Wak, 2008.

MESQUITA, D. A. SILVA, E. P. JÚNIOR, J. R. R. O psicólogo atuando junto a criança hospitalizada. 2013. Disponível em https://periodicos.set. edu.br/index.php/fitsbiosaude/article/download/621/369. Acesso em 08 mar. 2019.

OLIVEIRA, V. B. O Lúdico na Realidade Hospitalar. In: VIEGAS, D Brinquedoteca Hospitalar: isto é humanização. Associação Brasileira de Brinquedotecas. 2. ed. Rio de Janeiro: Wak, 2008.

SILVA, J. P. A Brinquedoteca Hospitalar e sua contribuição às crianças hospitalizadas: um estudo na pediatria do hospital geral de Bragança-Pará. 2012. Disponível em http://monografias.brasilescola.uol.com.br/educacao/ Brinquedoteca-hospitalar-contribuicao-criancas-hospitalizadas.htm. Acesso em 20 jan. 2019 